\title{
The Brown-Vialetto-Van Laere and Fazio Londe syndrome revisited: natural history, genetics, treatment and future perspectives
}

\author{
Annet M Bosch ${ }^{1 *}$, Kevin Stroek ${ }^{1}$ Nico G Abeling ${ }^{2}$, Hans R Waterham², Lodewijk IJlst ${ }^{2}$ and Ronald JA Wanders ${ }^{2}$
}

\begin{abstract}
The Brown-Vialetto-Van Laere syndrome is a rare neurological disorder which may present at all ages with sensorineural deafness, bulbar palsy and respiratory compromise. Fazio-Londe syndrome is considered to be the same disease entity. Recently it was demonstrated that in some patients the disease is caused by mutations in the SLC52A3 gene which encodes the intestinal (hRFT2) riboflavin transporter. In these patients riboflavin deficiency is the cause of the BWL/FL syndrome and supplementation of riboflavin proved a life saving treatment. Mutations in the SLC52A2 gene and the SLC52A1 (GPR172B) gene, coding for human riboflavin transporters hRFT3 and hRFT1 have been associated with the BWL syndrome as well. We performed a review of the literature, with emphasis on the natural history and the effects of treatment in these patients. A total of 35 publications were traced reporting on the clinical presentation of 74 patients who presented before age 18. The most prevalent symptoms were bulbar palsy, hearing loss, facial weakness and respiratory compromise. Death was reported in 28 of the 61 untreated patients, with a very low survival in patients presenting before age 4 . All 13 patients who were treated with riboflavin survived, with a strong clinical improvement after days to months of treatment in eight patients. Three patients demonstrated a stable clinical course and treatment was stopped early in two patients. Abnormalities in plasma flavin levels and/or plasma acylcarnitine profiles were observed in some but not in all patients, and also patients with normal plasma flavin levels and acylcarnitine profiles demonstrated a striking clinical improvement on riboflavin supplementation. It is now clear that proper diagnosis requires mutation analysis of all three transporter genes and treatment should be started immediately without first awaiting results of molecular analysis. Clinical improvement may be rapid or gradual over a period of more than 12 months.
\end{abstract}

Keywords: Brown-Vialetto-Van Laere syndrome, Fazio Londe syndrome, Riboflavin transporter, Riboflavin supplementation

\section{Introduction}

The Brown-Vialetto-Van Laere syndrome (BVVL) (MIM 211530, ORPHA97229) is a rare neurological disorder first described by Brown in 1894 and later by Vialetto and Van Laere. The prevalence is very low and only fifty-eight patients were reported by 2008 [1]. Patients mostly present with sensorineural deafness, bulbar palsy and respiratory compromise and the age of onset varies from infancy to adulthood [1]. In Fazio-Londe syndrome (FL) (MIM 211500, ORPHA56965) the clinical

\footnotetext{
* Correspondence: a.m.bosch@amc.uva.nl

${ }^{1}$ The Department of Pediatrics, University of Amsterdam, Amsterdam, The Netherlands

Full list of author information is available at the end of the article
}

presentation is the same, but without the hearing loss, and FL is considered to be the same disease entity as BVVL [2]. Bosch et al. [3] demonstrated the same homozygous mutation in two siblings who presented with BVVL and FL syndromes respectively [3].

In 2008 a detailed review of the literature was published by Sathasivam in this journal [1]. However, since 2010 insights into the pathophysiology, genetics and treatment of this disorder have increased tremendously. In 2010 Green et al. demonstrated that in some patients the disease is caused by mutations in the SLC52A3 gene (other aliases: BVVLS, BVVLS1, C20orf54, RFT2, RFVT3, bA371L19.1, hRFT2) [4], and in 2011 Bosch et al. demonstrated that this gene encodes the intestinal

\section{Biomed Central}


(hRFT2) riboflavin transporter and that in these patients riboflavin deficiency is the cause of the BVVL/FL syndrome [3]. Supplementation of riboflavin proved a life saving treatment for a number of young patients [3-7]. Inheritance is autosomal recessive $[3,4]$.

Recently, mutations in the SLC52A2 gene (other aliases: BVVLS2, D15Ertd747e, GPCR41, GPR172A, PAR1, RFT3, RFVT2, hRFT3) coding for another human riboflavin transporter (hRFT3) have been associated with the BVVL syndrome as well, again with favorable clinical effects of oral riboflavin supplementation [8,9]. Furthermore, Ho et al. [10] reported a newborn who presented with clinical features highly suggestive of multiple acylCoA dehydrogenase deficiency (MADD) resulting from maternal riboflavin deficiency [10]. The mother was was found to have a hemizygous deletion spanning exons 2 and 3 of the SLC52A1 gene (other aliases: GPCR42, GPR172B, PAR2, RFT1, RFVT1, hRFT1) which encodes another riboflavin transporter. The infant fully recovered after riboflavin treatment $[10,11]$.

Awareness of these new insights and therapeutic options among professionals is essential, especially since treatment appears to be lifesaving with obvious consequences for the outcomes of these patients. Therefore, we performed a review of the literature, with particular emphasis on the natural history and the effects of treatment in these patients, and provide advice on diagnostics and treatment based on the present knowledge.

\section{Methods}

\section{Literature search}

A search was done in Pubmed using the search terms 'Brown-Vialetto-Van Laere' and 'Fazio-Londe'. As these disorders are considered to be the same disease entity we will report all patients as having BVVL syndrome in this article [2,3]. We searched for publications in English. Every accessible publication published before September 1st 2012 was studied for case reports. All case reports were carefully analyzed for clinical aspects such as age at presentation, presenting symptoms, course of the disease, survival, treatment and genetics. Only patients who presented before the age of 18 were included and all patients described more than once were included only once. Case reports without sufficient information about age or symptoms were excluded. References were checked for other relevant publications, which did not result in additional publications since no additional patients were described in these publications. An additional search in EBSCO Medline gave no further relevant results.

\section{Results}

A total of 34 accessible publications was retrieved. Of one more article only the abstract was available but this provided enough information to be useful [12]. In these 35 publications 101 patients are described. After excluding doubles (10) and patients with a presentation at age 18 or above or no information about age (17), the data of 74 patients were analyzed [2-9,12-30].

\section{Patients}

Seventy-four case reports were analyzed. The group consisted of 23 males and 51 females. Because the incidence within this group varied with age, we decided to divide the patients in three age groups (Figure 1). Group 1 contains 21 patients with an age at presentation between 0 and 3 years. One of these patients was reported to present in infancy without an exact age. For this reason she was excluded from the group in which the presenting age was studied [28]. Group 2 contains 21 patients with a presenting age range of 4 through 10 years and group 3 contains 28 patients with a presenting age range of 11 through 17 years. Because four other patients were reported as "presenting in childhood", they could not be included in one particular group, but were included when we report on data of the complete patient group $[14,20,24,30]$.

\section{Natural history}

\section{Presenting age}

The age at presentation was known for 69 patients with a mean of 8.2 years (median 9, range $0.3-17$, SD 5.2). In group $1(\mathrm{~N}=21)$ the age at presentation was known for 20 patients and the mean presenting age was 1.4 years. In group $2(\mathrm{~N}=21)$ and in group $3(\mathrm{~N}=28)$ the mean presenting ages were 7.9 years and 13.3 years respectively (Table 1).

\section{Clinical presentation}

Symptoms of a total of 73 patients were reported. For one patient symptoms were not specified [24]. For the complete group the most prevalent symptoms were bulbar palsy (92\%), hearing loss (81\%), facial weakness

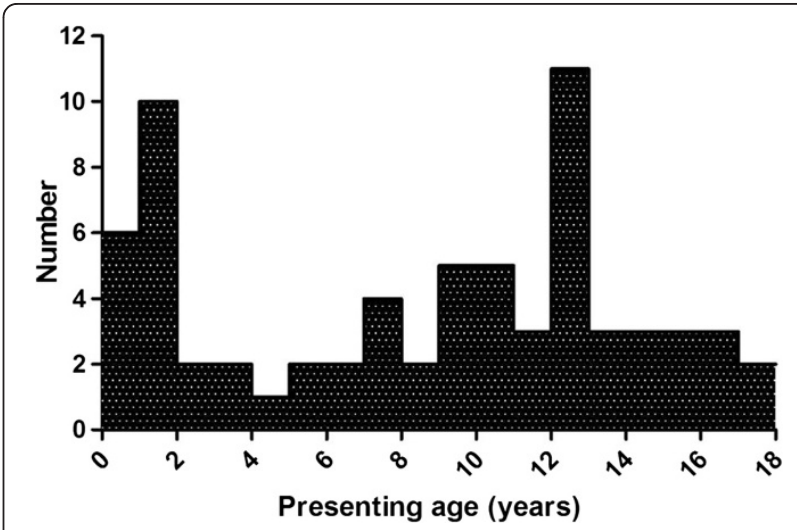

Figure 1 Number of patients by age of presentation. 
Table 1 Presenting age in years of all patients

\begin{tabular}{lllll}
\hline Presenting age (years) & Mean & Median & Age range & SD \\
\hline Group 1* $(\mathrm{N}=20)$ & 1.4 & 1.3 & $0.3-3.2$ & 0.8 \\
\hline Group 2* $(\mathrm{N}=21)$ & 7.9 & 8.0 & $4-10$ & 1.8 \\
\hline Group 3* $(\mathrm{N}=28)$ & 13.3 & 12.5 & $11-17$ & 1.8 \\
\hline All patients $(\mathrm{N}=69)$ & 8.2 & 9.0 & $0.3-17$ & 5.2 \\
\hline
\end{tabular}

*Group 1: age $<4$ years, Group 2: age 4-10 years, Group 3: age 11-17 years.

(77\%) and respiratory compromise (64\%). In group 1 $(\mathrm{N}=21)$ the most prevalent symptoms were respiratory compromise and bulbar palsy (both 86\%). Muscle weakness and hearing loss were found in $67 \%$ of patients. In all patients included in group $2(\mathrm{~N}=21)$ bulbar palsy was found, with facial weakness in $95 \%$, hearing loss in $90 \%$ and respiratory compromise in $62 \%$ of patients. In group $3(\mathrm{~N}=28)$ bulbar palsy $(89 \%)$, hearing loss $(86 \%)$, and facial weakness $(82 \%)$ were prevalent, with muscle weakness in $50 \%$ of patients (Table 2).

\section{Survival}

For this section patients who received riboflavin treatment were analyzed separately from the untreated patients. All 13 patients who received treatment survived [3,5-9].

In the 61 patients who did not receive riboflavin treatment death was reported in 28 of the patients (Table 3). Mean age of death was 11.6 years (median 9.3, range 0.9-42, SD 11.1). The mean time span between presentation and death was specified for 25 patients and was 5.0 years (median 1.3 , range $0-32$, SD 7.9). The patients were divided in three groups by the same age ranges as described earlier. In the untreated patients in group 1 $(\mathrm{N}=13)$, death was reported in 11 patients. Mean age of death was 1.9 years (median: 1.9; range: 0.9-3; SD: 0.6). The mean time span between presentation and death was 0.8 years (median: 0.6; range: 0.2-1.7; SD: 0.5). In 6 patients the cause of death was known and in all of them respiratory insufficiency was reported as the cause. In group $2(\mathrm{~N}=17) 9$ patients did not survive. Mean age of death was 18.5 years (median: 11; range: 10.5-42; SD: 11.0). The mean time span between presentation and death was 10.3 years (median: 3.5; range: 0.3-32; SD: 10.7). In 4 patients the cause of death was known and respiratory insufficiency was reported as cause of death in all 4 patients. In group $3(\mathrm{~N}=27)$ death was reported in 5 cases. Mean age of death was 18.5 years (median: 17.3; range: $12-25$; SD: 4.6). The mean time span between presentation and death was 4.7 years (median: 5.3; range: $0-10 ; \mathrm{SD}: 4.1)$. In 2 patients the cause of death was known and in both of them respiratory insufficiency was reported as the cause.

\section{Genetics}

Until now, 23 different mutations have been reported in the SLC52A3 gene in 23 patients included in this review $[3,4,6,7,9,13,20]$ (Table 4). Anand et al. [5] reported a pathogenic homozygous mutation in their patient without providing details on the mutation [5]. The mutations include frameshift, splice site, missense and nonsense mutations. By screening a cohort of patient suspected of BVVL syndrome Johnson et al. [9] demonstrated two

Table 2 Group 1, 2 and 3 symptoms

\begin{tabular}{|c|c|c|c|c|c|c|c|c|}
\hline & Group $1(\mathrm{~N}=21)$ & $\%$ & Group $2(\mathrm{~N}=21)$ & $\%$ & Group $3(\mathrm{~N}=28)$ & $\%$ & Total $(\mathrm{N}=73)$ & $\%$ \\
\hline Bulbar palsy (CN IX-XII) & 18 & $86 \%$ & 21 & $100 \%$ & 25 & $89 \%$ & 67 & $92 \%$ \\
\hline Hearing loss & 14 & $67 \%$ & 19 & $90 \%$ & 24 & $86 \%$ & 59 & $81 \%$ \\
\hline Facial weakness & 10 & $48 \%$ & 20 & $95 \%$ & 23 & $82 \%$ & 56 & $77 \%$ \\
\hline Respiratory compromise & 18 & $86 \%$ & 13 & $62 \%$ & 13 & $46 \%$ & 47 & $64 \%$ \\
\hline Muscle weakness & 14 & $67 \%$ & 10 & $48 \%$ & 14 & $50 \%$ & 40 & $55 \%$ \\
\hline Upper motor neuron signs & 3 & $14 \%$ & 10 & $48 \%$ & 11 & $39 \%$ & 26 & $36 \%$ \\
\hline Palsy of CN III, IV or VI & 9 & $43 \%$ & 5 & $24 \%$ & 7 & $25 \%$ & 23 & $32 \%$ \\
\hline Stridor & 10 & $48 \%$ & 3 & $14 \%$ & 4 & $14 \%$ & 18 & $25 \%$ \\
\hline Palsy of the trigeminal nerve $(\mathrm{V})$ & 1 & $5 \%$ & 6 & $29 \%$ & 6 & $21 \%$ & 14 & $19 \%$ \\
\hline Lower motor neuron signs & 4 & $19 \%$ & 5 & $24 \%$ & 4 & $14 \%$ & 13 & $18 \%$ \\
\hline Diaphragm weakness/palsy & 4 & $19 \%$ & 3 & $14 \%$ & 4 & $14 \%$ & 11 & $15 \%$ \\
\hline Palsy of the optic nerve (II) & 2 & $10 \%$ & 3 & $14 \%$ & 5 & $18 \%$ & 10 & $14 \%$ \\
\hline Ataxia & 2 & $10 \%$ & 3 & $14 \%$ & 3 & $11 \%$ & 9 & $12 \%$ \\
\hline Tremor & 2 & $10 \%$ & 1 & $5 \%$ & 3 & $11 \%$ & 6 & $8 \%$ \\
\hline Behavioral changes & 1 & $5 \%$ & 0 & $0 \%$ & 2 & $7 \%$ & 3 & $4 \%$ \\
\hline Mental retardation & 0 & $0 \%$ & 0 & $0 \%$ & 3 & $11 \%$ & 3 & $4 \%$ \\
\hline Epilepsy & 0 & $0 \%$ & 0 & $0 \%$ & 2 & $7 \%$ & 3 & $4 \%$ \\
\hline Autonomic dysfunction & 0 & $0 \%$ & 0 & $0 \%$ & 2 & $7 \%$ & 2 & $3 \%$ \\
\hline
\end{tabular}


Table 3 Age of death in years in patients who did not receive riboflavin treatment

\begin{tabular}{lllllll}
\hline $\begin{array}{l}\text { Age of death } \\
\text { (years) }\end{array}$ & $\begin{array}{l}\mathbf{N} \\
\text { deceased }\end{array}$ & $\begin{array}{l}\% \\
\text { deceased }\end{array}$ & $\begin{array}{l}\text { Mean } \\
\text { age }\end{array}$ & $\begin{array}{l}\text { Median } \\
\text { age }\end{array}$ & $\begin{array}{l}\text { Age } \\
\text { range }\end{array}$ & SD \\
\hline $\begin{array}{l}\text { Group 1* } \\
(\mathrm{N}=13)\end{array}$ & 11 & $85 \%$ & 1.9 & 1.9 & $0.9-3$ & 0.6 \\
\hline $\begin{array}{l}\text { Group } 2^{*} \\
(\mathrm{~N}=17)\end{array}$ & 9 & $53 \%$ & 18.5 & 11 & $7.3-42$ & 11.0 \\
\hline $\begin{array}{l}\text { Group 3* } \\
(\mathrm{N}=27)\end{array}$ & 5 & $19 \%$ & 18.5 & 17.3 & $12-25$ & 4.6 \\
\hline $\begin{array}{l}\text { All patients } \\
(\mathrm{N}=61)\end{array}$ & 28 & $46 \%$ & 11.6 & 9.3 & $0.9-42$ & 11.1 \\
\hline *Group 1: age <4 years, Group 2: age 4-10 years, Group 3: age & $11-17$ years.
\end{tabular}

*Group 1: age <4 years, Group 2: age 4-10 years, Group 3: age 11-17 years. more mutations in patients not included in the natural history review because clinical symptoms were not reported [9]. These two mutations are included in Table 4.

Recently, mutations have been demonstrated in the SLC52A2 gene which codes for hRFT3. Johnson et al. [9] demonstrated a homozygous missense mutation in two unrelated patients [9], whereas Haack et al. [8] reported the identification of two heterozygous mutations in one patient [8].

\section{Biochemical abnormalities}

Abnormalities in the acylcarnitine profiles were reported in 6 patients, of whom 4 patients demonstrated mutations in the SLC52A3 gene and 2 in the SLC52A2 gene

Table 4 Reported pathogenic mutations in the SLC52A3 gene

\begin{tabular}{|c|c|c|c|c|}
\hline \multicolumn{5}{|c|}{ A Reported pathogenic mutations in the $S L C 52 A 3$ gene } \\
\hline Mutation & Type & Exon & Coding effect & Reference (first report) \\
\hline C.49T>C & Missense & 2 & p.Trp17Arg & Bosch et al. [3] \\
\hline c. $62 A>G$ & Missense & 2 & p.Asn21Ser & Dezfouli et al. [13] \\
\hline $\mathrm{C} .82 \mathrm{C}>\mathrm{A}$ & Missense & 2 & p.Pro28Thr & Johnson [20] \\
\hline c. $106 G>A^{1}$ & Missense & 2 & p.Glu36Lys & Green et al. [4] \\
\hline c. $160 G>A$ & Missense & 2 & p.Gly54Arg & Johnson [9] \\
\hline c. $173 \mathrm{~T}>\mathrm{A}$ & Missense & 2 & p.Val58Asp & Ciccolella et al. [6] \\
\hline$c .211 G>A$ & Missense & 2 & p.Glu71Lys & Johnson. [20] \\
\hline$c .211 \mathrm{G}>\mathrm{T}$ & Nonsense & 2 & p.Glu71X & Green et al. [4] \\
\hline c.224T >C & Missense & 2 & p.lle75Thr & Johnson [9] \\
\hline c.394C>T & Missense & 2 & p.Arg132Trp & Green et al. [4] \\
\hline c.568-19_-18insCTGATTGAC & Insertion & $2 \mathrm{i}$ & Unknown & Ciccolella et al. [6] \\
\hline c.639C>G & Nonsense & 3 & p.Tyr213X & Green et al. [4] \\
\hline c.659C>A & Missense & 3 & p.Pro $220 \mathrm{His}$ & Dezfouli et al. [13] \\
\hline c.670T>C & Missense & 3 & p.Phe224Leu & Green et al. [4] \\
\hline c.796C>T & Missense & 3 & p.Arg266Trp & Ciccolella et al. [6] \\
\hline C.935C>T & Missense & 3 & p.Ala312Val & Dezfouli et al. [13] \\
\hline c.955C>T & Missense & 3 & p.Pro319Ser & Ciccolella et al. [6] \\
\hline c.989G $>\mathrm{T}$ & Missense & 3 & p.Gly330Val & Koy et al. [7] \\
\hline C. $1048 \mathrm{~T}>\mathrm{A}$ & Missense & 3 & p.Leu350Met & Green et al. [4] \\
\hline c.1325_1326delTG & Deletion & 5 & p.Leu442ArgfsX64 & Green et al. [4] \\
\hline C. $1198-2 A>C$ & Splice defect & $4 i$ & Unknown & Bosch et al. [3] \\
\hline C.1371C>G & Missense & 5 & p.Phe457Leu & Green et al. [4] \\
\hline c. $1296 C>A$ & Nonsense & 5 & p.Cys432X & Ciccolella et al. [6] \\
\hline C.1237T>C $\mathrm{C}^{1}$ & Missense & 5 & p.Val413Ala & Green et al. [4] \\
\hline C. $1238 \mathrm{~T}>\mathrm{C}$ & Missense & 5 & p.Val413Ala & Ciccolella et al. [6] \\
\hline \multicolumn{5}{|c|}{ B Reported pathogenic mutations in the $S L C 52 A 2$ gene } \\
\hline c.368T>C & Missense & & p.Leu123Pro & Haack et al. [8] \\
\hline C. $419 C>T^{2}$ & Missense & & p.Pro140Leu & Johnson et al. [9] \\
\hline$C .916 G>A^{2}$ & Missense & & p.Gly306Arg & Johnson et al. [9] \\
\hline C.1016T>C & Nonsense & & p.Leu339Pro & Haack et al. [8] \\
\hline
\end{tabular}

${ }^{1}$ c.106G $>$ A and c.1237T $>C$ are in cis. c.106G $>A$ is predicted to be deleterious; c.1237T >C is predicted to be tolerated (Green et al. [4]).

${ }^{2}$ c.419C $>$ T is reported in cis with pathogenic mutation c.916G $>A$ and is possibly non-pathogenic (Johnson et al. [9]). 
$[3,5,8,9]$. In 4 of these patients deficient flavin levels were found as well. All acylcarnitine profiles and flavin levels normalised after riboflavin supplementation.

\section{Treatment: riboflavin supplementation}

The effects of supplementation of riboflavin have been reported in 13 patients [3,5-9]. Eleven patients were treated with oral riboflavin, in two patients intravenous riboflavin supplementation was reported. Most patients were treated with a dose of $10 \mathrm{mg} / \mathrm{kg} /$ day. The mean age at the start of treatment was known for 11 patients and was 6.9 years (range: 3 months -17 years).

Eight of 13 treated patients demonstrated a strong clinical improvement. Seven of these patients were treated orally: one patient initially with a dose of $150 \mathrm{mg} /$ day at age 10 (which will be less than $10 \mathrm{mg} / \mathrm{kg} /$ day) which was increased to $450 \mathrm{mg} /$ day after 3 months, five with a dose of $10 \mathrm{mg} / \mathrm{kg} /$ day, and one patient with a dose of and $25 \mathrm{mg} / \mathrm{kg} /$ day. One patient was treated intravenously with $200 \mathrm{mg} /$ day at age 9 (less than 10 $\mathrm{mg} / \mathrm{kg} /$ day). The first signs of improvement were seen within days in some patients [3,5] with a more gradual improvement over many months in others $[3,5,6]$. Improvement was seen in muscle strength, motor function, respiration, hearing, and vision with a full recovery in some. Five patients were on mechanical ventilation (4 tracheostomy and 1 noninvasive ventilation) at the start of treatment. In all 4 patients with a tracheostomy, ventilation could be decreased or stopped. In the patient on noninvasive ventilation an improvement in diaphragm function was reported $[3,5,6]$.

In 6 of 8 riboflavin responsive patients MADD-like abnormalities were found in the acylcarnitine profile before treatment $[3,5,8,9]$ and in 4 of these patients deficient flavin levels were found as well. All acylcarnitine profiles and flavin levels normalised after riboflavin supplementation. Notably, 2 patients with normal acylcarnitine profiles, 3 patients with normal flavin levels, and one with unknown flavin levels before treatment was started, did demonstrate a strong clinical improvement after the start of treatment as well [6].

In all 8 patients who improved on riboflavin supplementation mutations were found in riboflavin transporter genes: in 6 patients mutations were demonstrated in the $S L C 52 A 3$ gene, whereas in 2 patients mutations were demonstrated in the SLC52A2 gene [8,9].

In 5 patients no improvement was demonstrated with riboflavin supplementation. Two of these patients were treated for a very short period: 1 discontinued treatment because of intolerance to oral riboflavin [6], and in one patient treatment was stopped already after 1 week due to lack of clinical improvement [7]. This last patient did demonstrate improvement in the following months but the relation between the improvement and the riboflavin supplementation has remained unclear. All three patients on prolonged riboflavin supplementation are reported to have a stable clinical situation but without improvement. The three stable patients and the patient who stopped treatment because of intolerance were all treated orally with $10 \mathrm{mg} / \mathrm{kg} /$ day. The patient who was considered unresponsive after one week of treatment was treated with $10 \mathrm{mg} / \mathrm{kg} /$ day intravenously. In four of the patients without improvement, acylcarnitine profiles and flavin levels had been studied and no abnormalities were found.

Mutations in the hRFT2 gene were found in two patients who did not improve on riboflavin: one of the patients with a stable clinical course and the patient in whom treatment was stopped after 1 week for lack of effect. The two patients with a stable condition but no clinical improvement after treatment, and the patient reported to be intolerant of riboflavin supplementation did not demonstrate mutations in SLC52A1, SLC52A2, or SLC52A3.

\section{Discussion and future perspectives}

This review of the literature demonstrates that - when untreated - BVVL is a severe disorder with a variable but mostly rapid downhill progression, especially in the younger age groups. Outcome is often fatal. As the diagnosis in the group of patients reported before 2010 was based on symptoms only, the disease in these patients may well result from a very diverse etiology.

Since 2010, a much more defined group of patients has been reported. The first publication reported only mutations in the hRFT2 gene and all patients demonstrated abnormalities in acylcarnitine profiles and flavin levels [3]. Since then it has become clear that mutations in all 3 transporters may cause BVVL syndrome [3,8-10].

The abnormalities in the acylcarnitine profiles in the first reported patients are explained by the fact that riboflavin is the precursor of FAD, which acts as an electron acceptor in a number of acyl-CoA dehydrogenation reactions involved in mitochondrial fatty acid oxidation and branched-chain amino acid catabolism [31]. From this first treated group of patients it has become clear that abnormalities in plasma flavin levels and/or plasma acylcarnitine profiles are observed in some, but not in all patients with a hRFT2 or a hRFT3 transporter defect. Importantly, also patients with normal plasma flavin levels and acylcarnitine profiles demonstrated a striking clinical improvement on riboflavin supplementation.

It is now clear that proper diagnosis requires mutation analysis of all three transporter genes. As we reported before, patients will not be detected by newborn screening with abnormal acylcarnitine profiles, probably because of supplementation of flavins from the mother [3]. Because of the striking and often lifesaving effects of 
riboflavin supplementation it is highly advisable to start treatment immediately without awaiting results of mutation analysis. Two patients in the treated group were treated for a very short period only: in 1 patient treatment was stopped because no clear clinical improvement was seen after 1 week of riboflavin supplementation [7]. However, while in some patients improvement has been demonstrated within days, other patients, and especially more severely affected patients demonstrated a more gradual improvement over a period of more than 12 months. Therefore treating physicians should be advised to continue the trial period for riboflavin supplementation for a longer period. Remarkably, the patient who was treated for 1 week improved in the following months but the relation between the short treatment period and the clinical improvement has remained unclear. Three treated patients who did not improve did however demonstrate a stable course, of which it is not possible to predict whether the course might have been less favorable without the supplementation.

In spite of the success of treatment in this first small group of patients, very little is yet known of the pathophysiology of the disorder, nor of the optimal dose, frequency or mode of administration of the riboflavin supplementation. Further studies into the riboflavin transport by the different transporters are urgently needed.

\section{Conclusion}

Untreated BVVL is a severe and often fatal disorder. In most patients with a proven hRFT defect riboflavin is highly effective and life saving, both in patients with and without a plasma flavin deficiency. The diagnosis can only be made or rejected by mutation analysis of all 3 genes encoding the hRFT family, and treatment should be started immediately without first awaiting results of molecular analysis. Clinical improvement may be rapid or gradual over a period of more than 12 months. We do recommend to rename this disease after its mechanism: Riboflavin transporter deficiency, type 1(hRFT1), 2 (hRFT2) and 3 (hRFT3).

\section{Competing interests}

The authors declare that they have no competing interests.

\section{Authors' contributions}

$A B$ was involved in design, acquisition and anaylsis of data, drafting of the manuscript. KS was involved in acquisition and analysis of data and drafting of the manuscript. NA was involved in design, analysis of data and critical revision of the manuscript. HW was involved in design, acquisition and analysis of data, drafting of the manuscript. LIJ was involved in design and critical revision of the manuscript. RW was involved in design, analysis of data and critical revision of the manuscript. All authors read and approved the final manuscript.

\section{Funding}

This study was funded by "Stichting Metakids", The Netherlands.

\section{Author details}

'The Department of Pediatrics, University of Amsterdam, Amsterdam, The Netherlands. ${ }^{2}$ Laboratory Genetic Metabolic Diseases, Academic Medical Center, University of Amsterdam, Amsterdam, The Netherlands.

Received: 5 October 2012 Accepted: 23 October 2012 Published: 29 October 2012

\section{References}

1. Sathasivam S: Brown-Vialetto-Van Laere syndrome. Orphanet J Rare Dis 2008, 3:9.

2. Dipti S, Childs AM, Livingston JH, Aggarwal AK, Miller M, Williams C, Crow YJ: Brown-Vialetto-Van Laere syndrome; variability in age at onset and disease progression highlighting the phenotypic overlap with FazioLonde disease. Brain Dev 2005, 27:443-446.

3. Bosch AM, Abeling NG, lijst L, Knoester H, van der Pol WL, Stroomer AE, Wanders RJ, Visser G, Wijburg FA, Duran M, Waterham HR: Brown-VialettoVan Laere and Fazio Londe syndrome is associated with a riboflavin transporter defect mimicking mild MADD: a new inborn error of metabolism with potential treatment. J Inherit Metab Dis 2011 , 34:159-164

4. Green P, Wiseman M, Crow YJ, Houlden H, Riphagen S, Lin JP, Raymond FL, Childs AM, Sheridan E, Edwards S, Josifova DJ: Brown-Vialetto-Van Laere syndrome, a ponto-bulbar palsy with deafness, is caused by mutations in c20orf54. Am J Hum Genet 2010, 86:485-489.

5. Anand G, Hasan N, Jayapal S, Huma Z, Ali T, Hull J, Blair E, McShane T, Jayawant S: Early use of high-dose riboflavin in a case of Brown-VialettoVan Laere syndrome. Dev Med Child Neurol 2012, 54:187-189.

6. Ciccolella M, Catteruccia M, Benedetti S, Moroni I, Uziel G, Pantaleoni C, Chiapparini L, Bizzi A, D'Amico A, Fattori F, Salsano ML, Pastore A, Tozzi G, Piemonte F, Bertini E: Brown-Vialetto-van Laere and Fazio-Londe overlap syndromes: A clinical, biochemical and genetic study. Neuromuscul Disord 2012, 21 [Epub ahead of print].

7. Koy A, Pillekamp F, Hoehn T, Waterham H, Klee D, Mayatepek E, Assmann B: Brown-Vialetto-Van Laere syndrome: a riboflavin-unresponsive patient with a novel mutation in the C20orf54 gene. Pediatr Neurol 2012, 46:407-409.

8. Haack TB, Makowski C, Yao Y, Graf E, Hempel M, Wieland T, Tauer U, Ahting U, Mayr JA, Freisinger P, Yoshimatsu H, Inui K, Strom TM, Meitinger T, Yonezawa A, Prokisch H: Impaired riboflavin transport due to missense mutations in SLC52A2 causes Brown-Vialetto-Van Laere syndrome. J Inherit Metab Dis 2012, 35(6):943-948.

9. Johnson JO, Gibbs JR, Megarbane A, Urtizberea JA, Hernandez DG, Foley AR, Arepalli S, Pandraud A, Simón-Sánchez J, Clayton P, Reilly MM, Muntoni F, Abramzon Y, Houlden $H$, Singleton AB: Exome sequencing reveals riboflavin transporter mutations as a cause of motor neuron disease. Brain 2012, 135:2875-2882.

10. Ho G, Yonezawa A, Masuda S, Inui K, Sim KG, Carpenter K, Olsen RK, Mitchell JJ, Rhead WJ, Peters G, Christodoulou J: Maternal riboflavin deficiency, resulting in transient neonatal-onset glutaric aciduria Type 2 , is caused by a microdeletion in the riboflavin transporter gene GPR172B. Hum Mutat 2011, 32:E1976-E1984.

11. Chiong MA, Sim KG, Carpenter K, Rhead W, Ho G, Olsen RK, Christodoulou J: Transient multiple acyl-CoA dehydrogenation deficiency in a newborn female caused by maternal riboflavin deficiency. Mol Genet Metab 2007, 92:109-114.

12. Aydin OF, Ozcelikel D, Senbil N, Gurer YK: Brown-Vialetto-van Laere syndrome; the first Turkish case. Acta Neuro Belg 2004, 104:111-113.

13. Dezfouli MA, Yadegari S, Nafissi S, Elahi E: Four novel C20orf54 mutations identified in Brown-Vialetto-Van Laere syndrome patients. J Hum Genet 2012, 57(9):613-617.

14. da Silva-Junior FP, Moura RD, Rosemberg S, Marchiori PE, Castro LH: Cor pulmonale in a patient with Brown-Vialetto-Van Laere syndrome: a case report. J Neurol Sci 2011, 300:155-156.

15. Descatha A, Goddet S, Aboab J, Allary J, Gergereau A, Baer M, Fletcher D: Cardiac arrest in a patient with Brown-Vialetto-Van Laere syndrome. Amyotroph Lateral Scle 2006, 7:187-188.

16. Fell D: Anesthesia in Brown-Vialetto-Van Laere syndrome. Paediat Anaesth 2009, 19:1130-1131. 
17. Gallai V, Hockaday JM, Hughes JT, Lane DJ, Oppenheimer DR, Rushworth G: Ponto-bulbar palsy with deafness (Brown-Vialetto-Van Laere syndrome). J Neurol Sci 1981, 50:259-275.

18. Gulati T, Dewan V, Kumar P, Ahuja B, Anand VK: Progressive bulbur paralysis (Fazio-Londe disease). Indian J Pediatr 2004, 71:101-102.

19. Hawkins SA, Nevin NC, Harding AE: Pontobulbar palsy and neurosensory deafness (Brown-Vialetto-Van Laere syndrome) with possible autosomal dominant inheritance. J Med Genet 1990, 27:176-179.

20. Johnson JO, Gibbs JR, Van ML, Houlden H, Singleton AB: Exome sequencing in Brown-Vialetto-van Laere syndrome. Am J Hum Genet 2010, 87:567-569.

21. Koc AF, Bozdemir H, Sarica Y: Mental retardation associated with BrownVialetto-Van Laere syndrome. Amyotroph Lateral Scler Other Motor Neuron Disord 2003, 4:52-53.

22. Koul R, Jain R, Chacko A, Alfutaisi A, Hashim J, Chacko J: Pontobulbar palsy and neurosensory deafness (Brown-Vialetto-van Laere syndrome) with hyperintense brainstem nuclei on magnetic resonance imaging: new finding in three siblings. J Child Neurol 2006, 21:523-525.

23. Malheiros JA, Camargos ST, Oliveira J, Cardoso FE: A Brazilian family with Brown-Vialetto-van Laere syndrome with autosomal recessive inheritance. Arq Neuropsiquiatr 2007, 65:32-35.

24. Mégarbané A, Desguerres I, Rizkallah E, Delague V, Nabbout R, Barois A, Urtizberea A: Brown-Vialetto-Van Laere syndrome in a large inbred Lebanese family: confirmation of autosomal recessive inheritance? Am J Med Genet 2000, 92:117-121.

25. Miao J, Li H, Lin H, Su C, Liu Y, Lei G, Yang T, Li Z: Severe sleep-disordered breathing in a patient with Brown-Vialetto-Van Laere syndrome: polysomnographic findings. J Neurol Sci 2007, 263:214-217.

26. Perticoni GF, Cantisani TA, Fisher H: Progressive bulbar paralysis in childhood: a case report. Ital J Neurol Sci 1983, 4:107-111.

27. Roeleveld-Versteegh AB, Braun KP, Smeitink JA, Dorland L, de Koning TJ: Mitochondrial respiratory chain disease presenting as progressive bulbar paralysis of childhood. J Inherit Metab Dis 2004, 27:281-283.

28. Sathasivam S, O'Sullivan S, Nicolson A, Tilley PJ, Shaw PJ: Brown-VialettoVan Laere syndrome: case report and literature review. Amyotroph Lateral Scler Other Motor Neuron Disord 2000, 1:277-281.

29. Voudris KA, Skardoutsou A, Vagiakou EA: Infantile progressive bulbar palsy with deafness. Brain Dev 2002, 24:732-735.

30. De Grandis D, Passadore P, Chinaglia M, Brazzo F, Ravenni R, Cudia P: Clinical features and neurophysiological follow-up in a case of Brown-Vialetto-Van Laere syndrome. Neuromuscul Disord 2005, 15:565-568.

31. Gregersen N, Andresen BS, Pedersen CB, Olsen RK, Corydon TJ, Bross P: Mitochondrial fatty acid oxidation defects-remaining challenges. J Inherit Metab Dis 2008, 31:643-657.

doi:10.1186/1750-1172-7-83

Cite this article as: Bosch et al: The Brown-Vialetto-Van Laere and Fazio Londe syndrome revisited: natural history, genetics, treatment and future perspectives. Orphanet Journal of Rare Diseases 2012 7:83.

\section{Submit your next manuscript to BioMed Central and take full advantage of:}

- Convenient online submission

- Thorough peer review

- No space constraints or color figure charges

- Immediate publication on acceptance

- Inclusion in PubMed, CAS, Scopus and Google Scholar

- Research which is freely available for redistribution 